УДК 378.4

СОДЕРЖАНИЕ КОНТИНУАЛЬНОГО ОБРАЗОВАНИЯ ПРИКЛАДНЫХ И АКАДЕМИЧЕСКИХ БАКАЛАВРОВ В УСЛОВИЯХ ПЕРМАНЕНТНОЙ МОДЕРНИЗАЦИИ ПРОФЕССИОНАЛЬНЫХ И ОБРАЗОВАТЕЛЬНЫХ СТАНДАРТОВ

\author{
${ }^{1}$ Абрамян Г.В., ${ }^{2}$ Катасонова Г.Р. \\ ${ }^{1}$ ГОУ ВПО «Финансовый университет при Правительстве РФ», \\ Санкт-Петербург, е-таil: spb_mail@fa.ru;

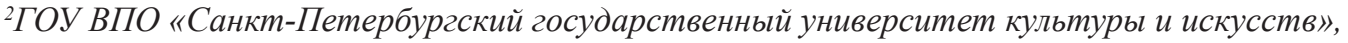 \\ Санкт-Петербург, e-mail: pk@spbguki.ru
}

\begin{abstract}
В статье рассматриваются основные тенденции, противоречия и проблемы формирования содержания континуального образования прикладных и академических бакалавров по направлениям подготовки «Бизнес-информатика» и «Прикладная информатика». Авторами выделены периоды разработки и сроки действия образовательных стандартов высшего профессионального образования РФ, а также связанные с ними особенности формирования структуры и содержания ООП. Исследование периодов действия стандартов позволило выделить этапы относительно стабильных и неустойчивых периодов развития содержания образования в вузах. Тенденции и противоречия, выявленные при сравнительном анализе структуры программ ФГОС ВПО и ФГОС ВО (3+) для бакалавров по направлениям подготовки «Бизнес-информатика» и «Прикладная информатика» в условиях перманентной модернизации профессиональных и образовательных стандартов, позволили разработать рекомендации руководителям, менеджменту среднего звена ОО и профессорско-преподавательскому составу вузов с учетом особенностей обновления содержания ООП в условиях перехода к ФГОС ВО (3+) и разрабатываемого ФГОС 4
\end{abstract}

Ключевые слова: модернизация образования, структура образовательной программы, содержание образования, образовательные стандарты, зачетные единицы, бизнес-информатика, прикладная информатика

\title{
CONTENTS OF CONTINUAL EDUCATION OF APPLIED AND ACADEMIC BACHELORS IN CONDITIONS OF PERMANENT MODERNIZATION OF VOCATIONAL AND EDUCATIONAL STANDARDS
}

\author{
${ }^{1}$ Abramyan G.V., ${ }^{2}$ Katasonova G.R. \\ ${ }^{1}$ Financial University under the Government of the Russian Federation, \\ St.Petersburg, e-mail: spb_mail@fa.ru; \\ ${ }^{2}$ Saint-Petersburg State University of Culture and Art, St. Petersburg, e-mail: pk@spbguki.ru

\begin{abstract}
The article examines the main trends, contradictions and problems of formation of the content of the continual education of applied and academic bachelors in the areas of training «Business Informatics» and «Applied Informatics». The authors highlighted during the development and duration of the educational standards of higher professional education of the Russian Federation, as well as the associated features of formation of structure and content. Study periods standards possible to identify the stages of relatively stable and unstable periods of curriculum development in universities. Trends and contradictions identified in the comparative analysis of the structure of Standard 3 programs and the Standard 3+ for bachelors in preparation directions «Business Informatics» and «Applied Computer Science» in the conditions of permanent modernization of professional and educational standards will develop recommendations executives, middle management and academic staff of universities allowing for the updating the content in the transition to Standard 3+ and developed by the Standard 4.
\end{abstract}

Keywords: modernization of education, the structure of the educational program, the content of education, educational standards, credit units, business computer science, applied computer science

Современная система высшего образования характеризуется процессами непрерывной модернизации и перестройки содержания образования, которые осуществляются на протяжении последних 25-30 лет. Анализ данных процессов позволяет выделить этапы относительно стабильных и неустойчивых периодов и проблем развития содержания образования на современном этапе [9]. Современные тенденции обновления содержания обра- зования прикладных и академических бакалавров заложены Федеральным законом «Об образовании», государственными и профессиональными стандартами, приказами и инструкциями Министерства образования, анализ которых позволяет выделить ряд периодов.

Первый период - нормативно-методический и правовой (начальный) функционирования основ содержания основной образовательной программы (ООП) 
бакалаврита и магистратуры был заложен с 1992 по 1994 год. В этот период разработана многоуровневая система высшего образования, которая была дополнена различными по характеру, объёму и содержанию образовательно-профессиональными программами различного уровня. Она должна была обеспечивать права обучаемых на выбор содержания и уровня своего образования и создать условия для гибкого реагирования высшей школы на запросы общества в условиях рыночной экономики, гуманизации образовательной системы. Система обучения данного периода учитывала Международную стандартную классификацию образования (МСКО) 1978 года для анализа и сбора образовательной статистики, а также ее представления на национальном и международном уровнях в соответствии с требованиями ЮНЕСКО.

Например, создание магистратуры в вузах Юга России началось на основании Постановления Государственного комитета по высшему образованию РФ от 10 сентября 1993 года № 42, утвердившего «Положение о магистерской подготовке (магистратуре) в системе многоуровнего высшего образования РФ». Статус магистратуры регламентировался Постановлением Правительства Российской Федерации от 12 августа 1994 года № 940 «Об утверждении государственного образовательного стандарта высшего профессионального образования» и Федеральным законом РФ «О высшем и послевузовском профессиональном образовании» 1996 года, в соответствии с которыми магистратура представляла собой одну из основных программ высшего профессионального образования со сроком освоения не менее шести лет для получения степени (квалификации) «магистр» и была ориентирована на научно-исследовательскую и (или) научно-педагогическую деятельность выпускников.

Меняющиеся социально-экономические условия $[1,2]$, формирующийся рынок интеллектуального труда [4, 8], развитие науки и техники $[5,11]$ предопределили необходимость постоянной работы по уточнению и оптимизации норм и положений ГОС ВПО [12]. На основе приказа Госкомвуза России от 5 марта 1994 г. был создан экспертный совет по Государственным образовательным стандартам, на который возложена обязанность регулярно рассматривать предложения учебно-методических объединений вузов по совершенствованию этих документов. ГОС ВПО определяли дифференциацию образования на уровне бакалавpa, магистра и специалиста. Это позволяло, с одной стороны, более гибко реагировать на потребности общества в специалистах разного уровня и квалификации, как того требовала рыночная экономика, с другой ГОС ВПО способствовали включению вузовской системы России в мировое культурно-образовательное пространство. Таким образом, ГОС ВПО как базовый нормативный документ, определяющий структуру и содержание высшего образования, создали основы для обеспечения необходимого качества обучения и поддержания единого образовательного пространства на всей территории России.

Утвержденная Министерством образования РФ структура стандартов представлена следующим образом: федеральный, национально-региональный компоненты и цикл курсов по выбору. Вузам предоставлено право самим формировать цикл гуманитарных и социально-экономических дисциплин. Из одиннадцати базовых дисциплин, приведенных в цикле общих гуманитарных и социально-экономических дисциплин, ГОС ВПО в качестве обязательных определил четыре - «Отечественную историю», «Философию», «Иностранный язык» и «Физическую культуру». Остальные базовые дисциплины реализовывались по усмотрению вузов.

На втором периоде - (1994-1999 гг.) были введены государственные образовательные стандарты высшего профессионального образования ГОС ВПО первого поколения. С точки зрения содержания стандарты ГОС ВПО содержали федеральный и региональный компоненты образования: федеральный - четко определял контуры федерального образовательного пространства в силу единства требований и вместе с тем выделял блоки, которые каждый преподаватель наполнял своим содержанием, предоставляя тем самым возможности для многообразия высшего образования; а второй - позволял еще более диверсифицировать высшее образование посредством преподавания дисциплин, охватывающих своеобразие регионов с их культурной, природной и этнической спецификой. В 1994 году был создан экспертный совет по Государственным образовательным стандартам, который занимался рассмотрением предложений по совершенствованию содержания и структуры ГОС ВПО от учебно-методических объединений вузов. А в 1996 г. Федеральным законом РФ «О высшем и послевузовском профессиональном образовании» были определены образовательные уровни (общее высшее, базовое высшее и полное высшее образование), а также сроки получения образования на каждом уровне и варианты соотношения 
содержания образовательных профессиональных программ.

В течение третьего периода (1995-1999 гг.) были разработаны и внедрены стандарты ГОС ВПО второго поколения, которые отличались от стандартов первого поколения как в содержательном, так и в структурных аспектах. Основной идеей новых стандартов была регионализация содержания образования на уровне образовательных организаций путем предоставления вузам большей самостоятельности в формировании содержания основной образовательной программы специалистов с учетом особенностей регионов и результатов исследований ведущих научных школ вузов. Государственный образовательный стандарт ВПО второго поколения определял структуру высшего профессионального образования, сохраненную практически без изменений относительно ГОС ВПО первого поколения, кроме того, в первоначальной редакции Закон не содержал положений о градации высшего образования на ступени (уровни). Между тем в период с 1992 года по 1998 гг. действовал закон РФ «Об образовании» в первой редакции, который на первом этапе изолировал процесс обучения от процесса воспитания, вследствие чего в учебных программах вузов значительно уменьшился духовно-нравственный компонент содержания обучения, однако впоследствии была разработана «Программа воспитания и образования» (1998-2012 гг.) для учреждений образования, которая кардинально изменила подходы к организации воспитательной работы со студентами.

С 2000 года ГОС ВПО первого поколения стали обязательными для выполнения по каждому направлению подготовки и ступеням образования, что послужило основой для официального присоединения России к Болонскому процессу в 2003 году. А в 2005 году были утверждены и стали обязательными ГОС ВПО второго поколения, ориентированные на получение студентами знаний, умений и навыков. В 2007 году существенно изменилась структура высшего образования - ступени высшего профессионального образования заменились двумя уровнями высшего образования.

Четвертый период связан с введением стандартов третьего поколения (ФГОС ВПО), которые были утверждены в 2009 г., в соответствии с которыми высшее образование должно в процессе обучения формировать у студентов общекультурные и профессиональные компетенции, в последствии, в 2012 году, стандарты ФГОС
ВПО были интегрированы с послевузовским профессиональным образованием.

В настоящее время внедряются образовательные стандарты ФГОС ВО (3+), которые утверждены в 2013 году Министерством образования и науки РФ. Например, в соответствии с п. 8.2 стандарта направления 350800 «Бизнес-информатика» оценка качества освоения содержания образовательных программ бакалавриата должна соответствовать требованиям рынка труда, профессиональным стандартам и устанавливаться процедурой профессиональнообщественной аккредитации образовательных программ (ОП).

При разработке и реализации содержания программ ФГОС ВО (3+) уровня бакалавриата образовательная организация ориентируется на конкретный вид профессиональной деятельности, к которому готовится бакалавр, исходя из потребностей рынка труда, научно-исследовательского и материально-технического ресурса образовательной организации (ОО) [6].

Для осуществления процедур текущего контроля успеваемости и промежуточной аттестации обучающихся образовательная организация (OO) создает и использует фонды оценочных средств, позволяющие оценить достижение запланированных в образовательных программах (ОП) результатов обучения и уровень сформированности компетенций, заявленных в ОП [7].

В целях приближения текущего контроля успеваемости и промежуточной аттестации обучающихся к задачам их будущей профессиональной деятельности ОО разрабатывает порядок и условия для привлечения к процедурам текущего контроля успеваемости, промежуточной аттестации, экспертизе оценочных средств внешних экспертов - работодателей из числа действующих руководителей и работников профильных организаций, имеющих стаж работы в конкретном виде профессиональной деятельности не менее 3 лет (например, аналитической, организационно-управленческой, проектной, научно-исследовательской, консалтинговой, инновационно-предпринимательской), а также преподавателей смежных образовательных областей, специалистов по разработке и сертификации оценочных средств $[3,10]$.

Например, стандарты ФГОС ВО (3+) предполагают переход к новой структуре и содержанию программ прикладных и академических бакалавров, в частности по направлениям подготовки 350800 «Бизнес-информатика» и 09.03.03 Прикладная информатика (табл. 1). 
Таблица 1

Структура программы прикладных и академических бакалавров по направлениям подготовки 350800 «Бизнес-информатика» и 09.03 .03 «Прикладная информатика»

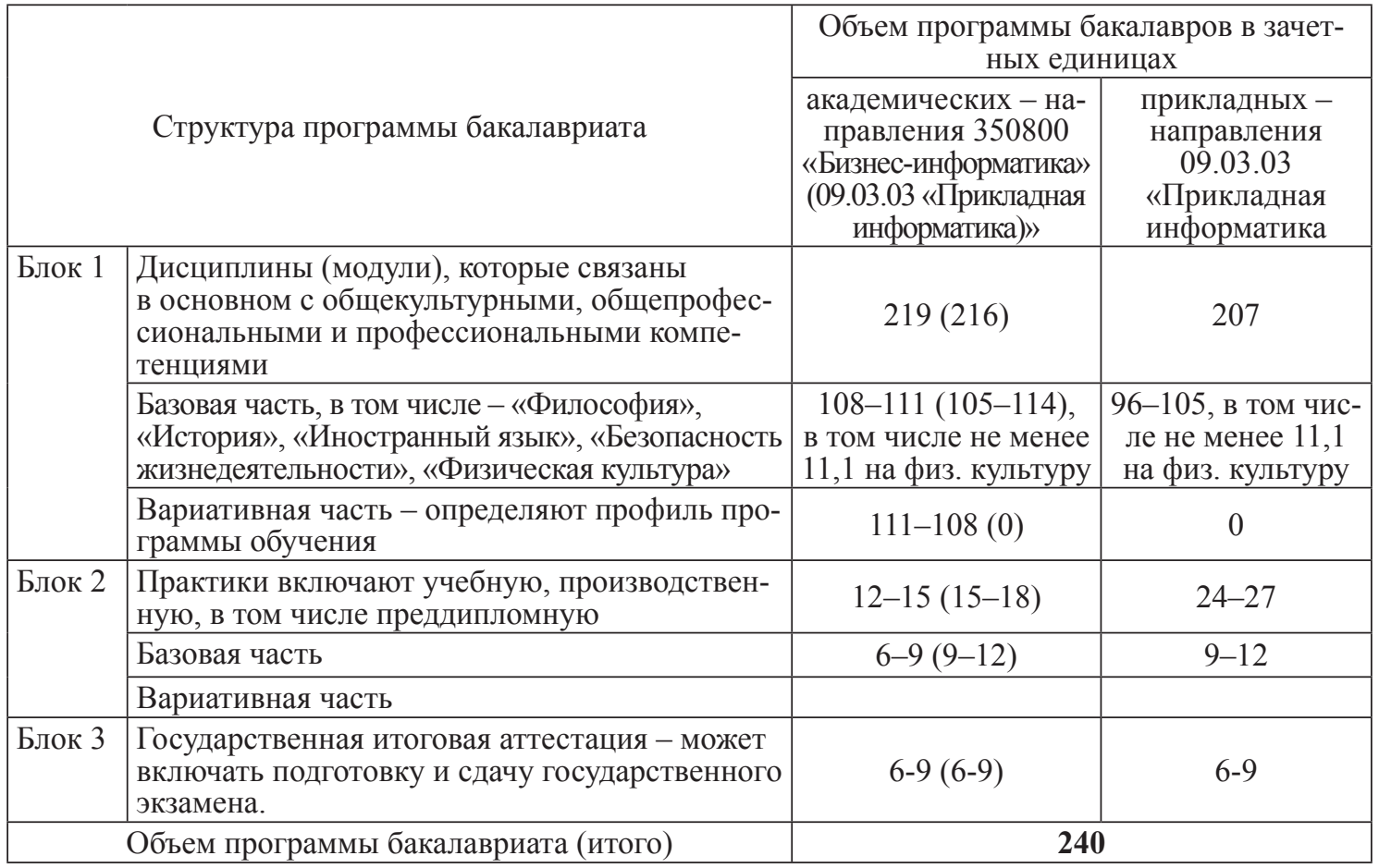

Таблица 2

Структура программы бакалавров направления подготовки 350800 «Бизнес-информатика»

\begin{tabular}{|c|l|c|}
\hline \multicolumn{2}{|c|}{ Структура программы бакалавриата } & $\begin{array}{c}\text { Объем про- } \\
\text { граммы в зач. } \\
\text { единицах }\end{array}$ \\
\hline \multirow{2}{*}{ Блок 1} & Дисциплины (модули) - Гуманитарный, социальный и экономический цикл & $34 / 43$ \\
\cline { 2 - 3 } & Вариативная часть & 9 \\
\hline \multirow{2}{*}{ Блок 2} & Математический и естественнонаучный цикл & $33 / 36$ \\
\cline { 2 - 3 } & Вариативная часть & 3 \\
\hline \multirow{2}{*}{ Блок 3} & Профессиональный цикл & 131 \\
\cline { 2 - 3 } & Базовая (общепрофессиональная) & 42 \\
\cline { 2 - 3 } & Вариативная часть & 99 \\
\hline Блок 4 & Физическая культура & 2 \\
\hline Блок 5 & Учебная практика & 12 \\
\hline Блок 6 & $\begin{array}{l}\text { Государственная итоговая аттестация - может включать подготовку и сда- } \\
\text { чу государственного экзамена }\end{array}$ & $\mathbf{2 4 0}$ \\
\hline \multicolumn{2}{|c|}{ Объем программы бакалавриата } & $\mathbf{2 4 0}$ \\
\hline
\end{tabular}

Структура и содержание программ бакалавров по направлению подготовки 350800 «Бизнес-информатика» представлены в табл. 2.

Сравнивая в представленных табл. 1 и 2 данные, можно выделить следующие тенденции и связанные с ними проблемы:

1) произошло объединение блоков 1,2 , 3,4 ФГОС ВПО в блок 1 ФГОС ВО;

2) блок 2 ФГОС ВО был образован из блока 5 ФГОС ВПО путем дифференциации базовой и вариативной частей;
3) несмотря на то, что объем ООП ФГОС ВО (3+) в целом не изменился и составляет 240 зачетных единиц, каждому вузу на основе определяемых стандартом компетенций необходимо будет самостоятельно:

a) разрабатывать перечень дисциплин гуманитарного, социального, экономического, математического и естественнонаучного циклов на основе определяемых стандартом компетенций; 
б) определять перечень, структуру и объемы дисциплин по базовой и вариативной компонентам - блока № 1 ООП с учетом увеличения объема кредитов со 210 до 219, что в среднем составляет около $5 \%$ или около 324 часов;

в) определять структуру и объем учебной, производственной и преддипломной практик с учетом увеличения с 8 до 12-15 кредитов, что в среднем составляет около $40 \%$ или от 144 до 252 часов;

г) определять структуру и объем государственной итоговой аттестации, допускающей возможность сдачи государственного экзамена с учетом уменьшения объема кредитов с 12 до 6-9, что составляет 35\% или от 108 до 216 часов (табл. 2).

При этом оценка качества освоения программ практик ФГОС ВО (3+) бакалавриата включает текущий контроль успеваемости, промежуточную аттестацию обучающихся с учетом конкретных форм и процедур, которые устанавливаются образовательной организацией самостоятельно на основе экспертизы оценочных средств внешних экспертов - работодателей из числа действующих руководителей и работников профильных организаций (имеющих стаж работы в данной профессиональной области не менее 3 лет), а также преподавателей смежных образовательных областей, специалистов по разработке и сертификации оценочных средств.

В соответствии с ФГОС ВО (3+) учебная и производственная практики проводятся в формах: научно-исследовательской работы, практики по получению профессиональных умений и опыта профессиональной деятельности, исполнительской, технологической практик, исполнительской практики, подготовки ВКР стационарным способом или на рабочем месте.

В соответствии с п. 8.5 стандарта ФГОС ВО (3+) обучающимся может быть предоставлена возможность оценивания содержания, организации и качества практик, а также работы отдельных преподавателей. В то время как в соответствии с ФГОС ВПО аттестация по итогам практики осуществлялась только в соответствии с ООП вуза. Таким образом, в условиях перманентной модернизации образовательных стандартов (с 1991 по 2015 гг.) и требований Министерства образования и науки РФ для перехода к подготовке прикладных и академических бакалавров начиная с 2014-2015 учебного года по направлению подготовки «Бизнесинформатика» необходимо решить следующие проблемы:

1) разработать методику закрепления компетенций за кафедрами и соответственно по дисциплинам;
2) учесть, что связанное с п. 1 перераспределение нагрузки (структуры и объема часов) между кафедрами приведет к изменению структуры и технологии реализации образовательной программы ФГОС ВО (3+), что может отразиться на качестве учебного процесса;

3) определить механизм экспертизы оценочных средств внешних экспертов;

4) определить критерии оценивания содержания, организации и качества практик с учетом работы отдельных преподавателей;

5) учесть, что качество образовательных программ ФГОС ВО (3+) вузов будет во многом зависеть от компетенции и опыта разработчиков ООП;

6) учесть, что в условиях большого количества различных по содержанию и структуре ООП вузов будут затруднены процессы перехода студентов из одного вуза в другой в связи с практикой расчета академической разницы по дисциплинарному признаку, но не по компетентностному;

7) учесть, что в новом стандарте предусмотрены формы и способы организации и проведения учебной и производственной практик, но не закреплены принципы обязательности их проведения.

Таким образом, в условиях перманентной модернизации профессиональных и образовательных стандартов и в частности для перехода на ФГОС ВО (3+) и ФГОС 4 в настоящее время руководителям и менеджменту среднего звена ОО, а также профессорско-преподавательскому составу вузов необходимо:

1) значительно усилить интеллектуальные, организационные, временные, кадровые и материальные ресурсы и затраты;

2) четко обозначить и уточнить цели перехода ОО на ФГОС ВО (3+) ФГОС 4 и поэтому, на наш взгляд, необходимы дополнительные научные исследования в области анализа структуры содержания ООП передовых вузов (прежде всего восточноевропейских, южноамериканских и азиатско-тихоокеанских), в частности в области IT с целью координации усилий, уточнения и проверки правильности принимаемых решений и действий в данном направлении;

3) содержание континуального образования прикладных и академических бакалавров в условиях перманентной модернизации профессиональных и образовательных стандартов все более и более характеризуется стохастическими переходными процессами, увеличением информационной неопределенности (энтропии) основных показателей и характеристик образовательных моделей и траекторий развития: целей, результатов и средств обучения, 
содержания обучения, компетенций, знаний, умений, навыков, опыта деятельности, эмоционально-ценностностных отношений, традиционных и инновационных методов обучения, форм и способов обучения и контроля $[13,15]$ SaaS, SLA, SoD, IaaS, PaaS концептуальных, виртуальных и сетевых распределенных моделей, технологий и сервисов поддержки образовательных услуг, инструментов и средств управления учебным процессом [14], экономико-финансовых, инвестиционных и маркетингово-рекламных характеристик и показателей учебного процесса, индивидуально-личностных характеристик субъекта обучения, требований, стандартов и рекомендаций в области обучения российских и международных комитетов, студенческих ассоциаций, профессиональных сообществ, как Болонская группа, МВА, Российский Союз Молодежи (PCM), AIESEC, BEST, АПКИТ.

\section{Список литературы}

1. Абрамян Г.В. Модели научного сотрудничества и профессионального образования в информационной среде стран Азиатско-Тихоокеанского экономического сотрудничества (АТЭС) // Информационно-телекоммуникационные системы и технологии» (ИТСиТ-2014): материалы Всероссийской научно-практической конференции. - Кемерово, 2014. - C. 7-8.

2. Абрамян Г.В. Система международного научного сотрудничества и модели глобализации профессионального образования и науки в информационной среде стран БРИКС // Региональная информатика «РИ-2014»: материаль XIV Санкт-Петербургской международной конференции. 2014. - C. 290-291

3. Абрамян Г.В. Теоретические основы профессионального становления педагога в информационной среде: дис. ... д-ра пед. наук : 13.00.08; РАО ИОВ; ЛГОУ им. А.С. Пушкина. - Защищена 25.01.2002. - СПб., 2001. - 510 с.: ил. - Библиогр.: С. 457-482.

4. Абрамян Г.В., Катасонова Г.Р. Интеграция и использование электронных и традиционных форм обучения информатике и информационным технологиям в экономических вузах с использованием информационных технологий управления [Электронный ресурс] // Современные проблемы науки и образования. - 2014. - № 5. - С. 1. - Режим доступа: http://www.science-education.ru/119-14259 (Дата обращения: 02.05.2015)

5. Абрамян Г.В., Катасонова Г.Р. Методология формирования и реализации систем интеллектуальной поддержки принятия решения при управлении предприятиями сферы финансов, экономики и образования // Перспективы и пути развития образования в России и в мире: материалы II Международной научно-практической конференции. Российская правовая академия Министерства юстиции Российской Федерации, Северо-Кавказский (г. Махачкала) филиал; Дагестанский институт повышения квалификации педагогических кадров. - 2013. - С. 14-21.

6. Абрамян Г.В., Катасонова Г.Р. Проектирование компонентов методической системы обучения студентов информатике и информационным технологиям в экономических вузах с использованием современных методологий на основе информационных технологий управления [Электронный pecypc] // Современные проблемы науки и образования. 2014. - № 4. - C. 49. - http:www.science-education.ru/11814000 (Дата обращения: 02.05.2015).
7. Абрамян Г.В., Катасонова Г.Р. Системы моделирования информационных процессов управления в сервисе // Региональная информатика «РИ-2012»: материалы юбилейной XIII Санкт-Петербургской Международной конференции. 2012. - C. 300.

8. Абрамян Г.В., Катасонова Г.Р. Таксономия, классификация и методология анализа целей обучения информатике и информационным технологиям в условиях глобализации образования [Электронный ресурс] // Фундаментальные исследования. - 2014. - № 8-7. - C. 1647-1652. http://www.rae. $\mathrm{ru} / \mathrm{fs} / \mathrm{pdf} / 2014 / 8-7 / 35270 . p d f$ (Дата обращения: 23.02.2015)

9. Абрамян Г.В., Марон А.Е. Стратегия и технология развития систем опережающего образования в современных условиях // Содержание и технологии образования взрослых: проблема опережающего обучения: сборник научных трудов. Гос. науч. учреждение «Ин-т образования взрослых Российской акад. образования»; под ред. А.Е. Марона. СПб., 2007. - С. 12-13.

10. Абрамян Г.В., Фокин Р.Р., Абиссова М.А. Инновационные подходы в области обработки данных экспериментов по автоматизации систем управления вузом и обучения информационным технологиям в высшей школе // Письма в Эмиссия. Оффлайн (The Emissia.Offline Letters): электронный научный журнал. - 2012. - № 11. - С. 1898

11. Вольфсон М.Б., Сотников А.Д. Модели и архитектуры электронного предприятия; под ред. Ю.В. Арзуманяна. - СПб.: Изд-во «Деан», 2009. - 272 с.

12. Деревянко Ю.Д., Изранцев В.В., Рыпин Б.И., Соколов Н.Е. Управление проектом создания электронного учебно-методического комплекса вуза // Профессиональное образование, наука, инновации в XXI веке: труды первого Санкт-Петербургского конгресса. - СПб.: Изд-во СПбГУ ИТМО, 2007. - С. 147-149.

13. Катасонова Г.Р. Проблемы обучения информационным технологиям управления и пути их решения на основе методологии метамоделирования, сервисов и технологий открытых систем // Известия Российского государственного педагогического университета им. А.И. Герцена. - 2014. № 167. - С. 105-114.

14. Катасонова Г.Р. Интерактивные технологии в обучении // Труды Санкт-Петербургского государственного университета культуры и искусств. - 2013. - Т. 200. C. 24-29.

15. Сотников А.Д., Арзуманян М.Ю. Сервис-ориентированная модель описания информационно-функциональных взаимодействий предприятия // Проблемы современной экономики. - 2009. - № 2. - С. 125-129.

\section{References}

1. Abramjan G.V. Modeli nauchnogo sotrudnichestva i professionalnogo obrazovanija $\mathrm{V}$ informacionnoj srede stran Aziatsko-Tihookeanskogo jekonomicheskogo sotrudnichestva (ATJeS) // Informacionno-telekommunikacionnye sistemy i tehnologii» (ITSiT-2014): materialy Vserossijskoj nauchno-prakticheskoj konferencii. Kemerovo, 2014. pp. 7-8.

2. Abramjan G.V. Sistema mezhdunarodnogo nauchnogo sotrudnichestva i modeli globalizacii professionalnogo obrazovanija i nauki v informacionnoj srede stran BRIKS // Regionalnaja informatika «RI-2014»: materialy XIV Sankt-Peterburgskoj mezhdunarodnoj konferencii. 2014. pp. 290-291.

3. Abramjan G.V. Teoreticheskie osnovy professionalnogo stanovlenija pedagoga $\mathrm{V}$ informacionnoj srede: dis. .. d-ra ped. nauk: 13.00.08; RAO IOV; LGOU im. A.S. Pushkina. Zashhishhena 25.01.2002. SPb., 2001. 510 s.: il. Bibliogr.: pp. $457-482$.

4. Abramjan G.V., Katasonova G.R. Integracija i ispolzovanie jelektronnyh i tradicionnyh form obuchenija informatike $\mathrm{i}$ informacionnym tehnologijam $\mathrm{v}$ jekonomicheskih vuzah $\mathrm{s}$ ispolzovaniem informacionnyh tehnologij upravlenija [Jelektronnyj resurs] // Sovremennye problemy nauki i obrazovanija. 2014. no. 5. pp. 1. Rezhim dostupa: http://www.science-education.ru/119-14259 (Data obrashhenija: 02.05.2015). 
5. Abramjan G.V., Katasonova G.R. Metodologija formirovanija i realizacii sistem intellektualnoj podderzhki prinjatija reshenija pri upravlenii predprijatijami sfery finansov, jekonomiki i obrazovanija // Perspektivy i puti razvitija obrazovanija v Rossii i v mire: materialy II Mezhdunarodnoj nauchno-prakticheskoj konferencii. Rossijskaja pravovaja akademija Ministerstva justicii Rossijskoj Federacii, Severo-Kavkazskij (g. Mahachkala) filial; Dagestanskij institut povyshenija kvalifikacii pedagogicheskih kadrov. 2013. pp. 14-21.

6. Abramjan G.V., Katasonova G.R. Proektirovanie komponentov metodicheskoj sistemy obuchenija studentov informatike i informacionnym tehnologijam $\mathrm{v}$ jekonomicheskih vuzah s ispolzovaniem sovremennyh metodologij na osnove informacionnyh tehnologij upravlenija [Jelektronnyj resurs] // Sovremennye problemy nauki i obrazovanija. 2014. no. 4 pp. 49. http:www.science-education.ru/118-14000 (Data obrashhenija: 02.05.2015).

7. Abramjan G.V., Katasonova G.R. Sistemy modelirovanija informacionnyh processov upravlenija v servise // Regionalnaja informatika «RI-2012»: materialy jubilejnoj XIII SanktPeterburgskoj Mezhdunarodnoj konferencii. 2012. pp. 300.

8. Abramjan G.V., Katasonova G.R. Taksonomija, klassifikacija i metodologija analiza celej obuchenija informatike $\mathrm{i}$ informacionnym tehnologijam $\mathrm{v}$ uslovijah globalizacii obrazovanija [Jelektronnyj resurs] // Fundamentalnye issledovanija 2014. no. 8-7. pp. 1647-1652. http://www.rae.ru/fs/pdf/2014/8 7/35270.pdf (Data obrashhenija: 23.02.2015)

9. Abramjan G.V., Maron A.E. Strategija i tehnologija razvitija sistem operezhajushhego obrazovanija $\mathrm{v}$ sovremennyh uslovijah // Soderzhanie i tehnologii obrazovanija vzroslyh: problema operezhajushhego obuchenija: sbornik nauchnyh trudov. Gos. nauch. uchrezhdenie «In-t obrazovanija vzroslyh Rossijskoj akad. obrazovanija»; pod red. A.E. Marona. SPb., 2007. pp. 12-13.

10. Abramjan G.V., Fokin R.R., Abissova M.A. Innovacionnye podhody v oblasti obrabotki dannyh jeksperimentov po avtomatizacii sistem upravlenija vuzom i obuchenija informacionnym tehnologijam v vysshej shkole // Pisma v Jemissija. Of- flajn (The Emissia.Offline Letters): jelektronnyj nauchnyj zhurnal. 2012. no. 11. pp. 1898

11. Volfson M.B., Sotnikov A.D. Modeli i arhitektury jelektronnogo predprijatija; pod red. Ju.V. Arzumanjana. SPb.: Izdvo «Dean», 2009. $272 \mathrm{p}$

12. Derevjanko Ju.D., Izrancev V.V., Rypin B.I., Sokolov N.E. Upravlenie proektom sozdanija jelektronnogo uchebnometodicheskogo kompleksa vuza// Professionalnoe obrazovanie, nauka, innovacii v XXI veke: trudy pervogo SanktPeterburgskogo kongressa. $\mathrm{SPb}$.: Izd-vo SPbGU ITMO, 2007. pp. 147-149.

13. Katasonova G.R. Problemy obuchenija informacionnym tehnologijam upravlenija i puti ih reshenija na osnove metodologii metamodelirovanija, servisov i tehnologij otkrytyh sistem // Izvestija Rossijskogo gosudarstvennogo pedagogicheskogo universiteta im. A.I. Gercena. 2014. no. 167. pp. 105-114.

14. Katasonova G.R. Interaktivnye tehnologii v obuchenii // Trudy Sankt-Peterburgskogo gosudarstvennogo universiteta kultury i iskusstv. 2013. T. 200. pp. 24-29.

15. Sotnikov A.D., Arzumanjan M.Ju. Servis-orientirovannaja model opisanija informacionno-funkcionalnyh vzaimodejstvij predprijatija // Problemy sovremennoj jekonomiki. 2009. no. 2. pp. $125-129$.

\section{Рецензенты:}

Соколов А.В., д.п.н., профессор кафедры информационных систем и мультимедиа, Санкт-Петербургский государственный университет культуры и искусств, г. СанктПетербург;

Фокин Р.Р., д.П.н., профессор кафедры «Бизнес-информатика», Санкт-Петербургский филиал Финансовый университет при Правительстве Российской Федерации, г. Санкт-Петербург. 